\title{
Inappropriate antibiotic use for respiratory infections in outpatient settings
}

\author{
Saman O mer ${ }^{1}$, Bushra T ayyaba K han², O mer Jali ${ }^{3}$, M uhammad W aqar Aslam K han², Q uratulain M ehdi ${ }^{1}$, \\ M ahjabeen Sharif 4 \\ ${ }^{1}$ Postgraduate T rainee, ${ }^{2}$ Associate Professor, Department of Pharmacology and Therapeutics Army M edical College, $\mathrm{N}$ ational U niversity of \\ M edical Sciences, Rawalpindi, Pakistan, ${ }^{3}$ Assistant Professor, M ohi ud D in Islamic M edical U niversity, M irpur K ashmir, Pakistan, ${ }^{4}$ Assistant \\ Professor, D epartment of Pharmacology and T herapeutics, Army M edical C ollege, $\mathrm{N}$ ational U niversity of M edical Sciences, Rawal pindi, Pakistan \\ Correspondence to: Saman O mer, E mail: samanayazch@hotmail.com
}

\begin{abstract}
Background: 0 veruse of antibiotics is a significant problem in low- and middle-income countries where recommended treatment guidelines are not routinely practiced, resulting in antimicrobial resistance. Acute respiratory tract infections, mostly viral in origin, remain the clinical category for most commonly prescribed antibiotics. D ue to the lack of local evidence about antibiotic prescribing trends in such infections, this study was conducted to evaluate the prescribing patterns in general and antibiotic prescribing trends specifically in prescriptions with the diagnosis of acute respiratory infections in district $\mathrm{M}$ irpur of Azad $\mathrm{K}$ ashmir.

Patients and methods: A prospective cross-sectional study carried out in the Department of Pharmacology and Therapeutics, Army Medical College, Rawalpindi, and outpatient departments of public health facilities in district $M$ irpur, Kashmir, from Aug to $O$ ct 2020. D ata were collected from 10 different public health facilities in District $\mathrm{M}$ irpur, $\mathrm{K}$ ashmir including, three rural health centers (RHC) and five basic health units (BH U). Prescribing pattern analysis by objective observations of the prescriptions after patient-physician encounter against the $\mathrm{W}$ orld $\mathrm{H}$ ealth Organization defined core prescribing indicators. The appropriateness of antibiotic use was analyzed against clinical practice guidelines. IBM SPSS Statistics for W indows, V ersion 26 was used for data analysis. D escriptive analysis was done to find frequencies and percentages for categorical data and means and standard deviation for continuous data.

Results: T otal number of prescriptions evaluated was 144. N umber of prescriptions containing antibiotics was 118 $(82 \%)$ (standard, $20-26.8 \%$ ). Inappropriate use of antibiotics was seen in $78 \%$ of cases where no antibiotics were indicated. The average number of medicines per prescription was 3.11 (standard, 2.1), whereas $79 \%$ of medicines prescribed were from the national essential medicine list (standard, 100\%). Only 2.5\% (standard, 100\%) of the medications were prescribed with generic names.

Conclusion: This study shows an inappropriate and overuse of antibiotics for acute respiratory tract infections, indicating a lack of adherence to core prescribing indicators and clinical guidelines by the physicians in outpatient clinics of M irpur.

Keywords:

Antibiotics, Prescriptions, Respiratory tract infections, W orld health organization, M irpur Azad Kashmir
\end{abstract}

\section{INTRODUCTION}

Antibiotics can serve as a disease-specific indicator for specific conditions such as acute respiratory tract infections to gain insight, as inappropriate prescribing of antibiotics is common in such infections despite mainly being viral in origin. ${ }^{1}$ Inappropriate use of antibiotics is one of the major factors leading to antimicrobial resistance ${ }^{2}$ leading to higher treatment cost because of the dependence on expensive alternative antibiotics and longer duration of illness ${ }^{3}$. The impact of antimicrobial resistance is higher in developing

Conflict of interest: $T$ he authors declared no conflict of interest exists.

Citation: Omer S, Khan BT, Jalil O, Khan MWA, Mehdi Q, Sharif M Inappropriate antibiotic use for respiratory infections in outpatient settings. J

Fatima Jinnah M ed U niv. 2021; 15(2):67-71.

D OI: https://doi.org/10.37018/D QUY6587 countries like Pakistan because of poor existing infrastructure and financial constraints to combat the epidemics of drug resistance ${ }^{4}$. There is a lack of national data on the use of antibiotics in Pakistan. However, available local data showed a very high percentage of prescription encounters with antibiotics ranging from 52 to $70 \%{ }^{5}$. To improve the appropriateness of prescribing, it is necessary to ascertain the current trends being practiced, but there is no data available to date on prescribing practices in respiratory tract infections in Azad K ashmir. T herefore, this study was conducted to find out the medicine prescribing patterns in general and antibiotic prescribing trends in particular in prescriptions of patients diagnosed with respiratory infections at the outpatient settings of district M irpur of Azad K ashmir. 


\section{PATIENTS AND METHODS}

The ethical review committee approved the protocol of Centre for Research in Experimental and Applied Medicine (CREAM )", Army M edical College $\mathrm{N}$ ational University of Medical Sciences, Rawalpindi Army $M$ edical College (ERC/ID/ 89). In addition, permission to collect data from the health facilities was obtained from the district health officer. Consent was obtained verbally from each study participant before the objective observation of prescriptions. The data was coded and then entered to keep the identities of patients and prescribers confidential.

This was a cross-sectional study from August to O ctober 2020. Data were collected from 10 different public health facilities in District $M$ irpur, Kashmir, including a district headquarters (DHQ) hospital, a tehsil headquarters (THQ) hospital, three rural health centers $(\mathrm{RHC})$, and five basic health units (BHU) keeping appropriate representation from urban, semiurban and rural facilities. The selection of health care facilities such as RHC and BHU was carried out after discussion and approval by the local health administration, considering convenience, accessibility, and other logistic aspects. The guidance for this sample size selection and survey methodology was taken from validated World $\mathrm{H}$ ealth Organization (W HO) developed guidelines ${ }^{6}$. According to W $\mathrm{HO}$ guidelines on investigating antimicrobial use patterns in health facilities, at least 100 encounters should be included in any study investigating prescribing patterns ${ }^{7}$.

$\mathrm{N}$ on-probability purposive sampling technique was used, and the primary author did the collection and objective observations of the prescriptions carried by the patients. The patient's visit to the health facility and their encounter with the prescriber was taken as a unit for analysis.

Prescriptions of the patients of all age groups attending the outpatient health facility were included. The prescribed medicines were counted as antimicrobial according to the criteria mentioned in the WHO manual of using drugs. Drugs such as antileprosy, anti-tuberculosis, antifungal, anti-amoebic, anti-giardiasis, anti-leishmaniasis, anti-trypanosomal, and antimalarial drugs are placed in a separate category from other antibiotics and therefore were not considered among antibiotics ${ }^{8}$.

The selection of prescriptions to be included was based on written diagnosis and treatment prescribed irrespective of the level of the prescriber's experience. Prescriptions with the diagnosis of upper respiratory tract infections (tonsillitis, pharyngitis, rhinitis, common cold, sore throat, cough, or otitis media) and lower tract infections (acute bronchitis, bronchiolitis, pneumonia) were included in the study'. The prescription encounters without the written diagnosis in the above categories but with cough and sore throat were also analyzed.

The appropriateness of antibiotic use in RT I was analyzed against the international clinical practice guideline recommendations from professional societies as no national guidelines were available $\mathrm{e}^{10}$. Common respiratory tract infections were classified into three tiers based on the most likely indication for an antibiotic's prescription. T ier 1 diagnoses are the ones for which antibiotics are almost always indicated and include pneumonia. T ier 2 diagnoses are the conditions for which antibiotics may be indicated, including sinusitis, suppurative otitis media, and pharyngitis. T ier 3 diagnoses are all other conditions for which antibiotics are not indicated and include asthma, allergy, bronchitis and bronchiolitis, influenza, nonsuppurative otitis media, a viral upper respiratory infection.

In addition to the antibiotic prescribing patterns, the prescriptions were also analyzed for the other W HO core prescribing indicators: (1) average number of drugs per patient encounter; to evaluate the degree of polypharmacy. Combination drugs were counted as one. (2) percentage of drugs prescribed by generic name; check the tendency to prescribe by generic name ${ }^{11}$. G enerics were defined as an international nonproprietary name (IN N) as per W HO guidelines. IN N prescribing is statutory in many countries and a standard practice without legal obligation in other names; therefore, this list was used as a guide in measuring this indicator ${ }^{12}$.

(3) Percentage of encounters with an injectable to determine the extent of use of these costly forms of medicine, (4) Percentage of drugs prescribed from the national essential drug list; to measure the degree to which practitioners stick to the $\mathrm{N}$ ational Drug Policy. $\mathrm{N}$ ational Essential $\mathrm{M}$ edicine List of Pakistan, published in 2018 by the Drug Regulatory Authority of Pakistan, was used as a reference ${ }^{13}$.

IBM SPSS Statistics for W indows, Version 26 was used for data analysis. D escriptive analysis was done to find frequencies and percentages for categorical data and means and standard deviation for continuous data. Results of the study analyzed WHO parameters for prescribing indicators. 
Table 1. Analyses of prescribing indicators

\begin{tabular}{lcc}
\hline \multicolumn{1}{c}{ Core Prescribing Indicator } & Average/Percentage & W H O Standard \\
\hline Average medicines per prescriptions & 3.11 & $1.6-1.8$ \\
\hline Prescriptions with antibiotics & $82 \%$ & $20.0-26.8$ \\
\hline Prescriptions with injections & $3 \%$ & $13.4-24.1$ \\
\hline M edicines from the essential drug list & $79 \%$ & 100 \\
\hline M edicines with generic names & $2.5 \%$ & 100 \\
\hline
\end{tabular}

Table 2. D iagnosis categories based on most likely indication for an antibiotic prescription in a tiered fashion

\begin{tabular}{lccc}
\multicolumn{1}{c}{ Diagnosis } & N umber of prescriptions $(n)$ & $\begin{array}{c}\text { N umber of prescriptions with } \\
\text { antibiotics prescribed }\end{array}$ & $\begin{array}{c}\text { Percentage of prescriptions with } \\
\text { antibiotics prescribed (\%) }\end{array}$ \\
\hline $\begin{array}{l}\text { Tier 1 (antibiotics almost always } \\
\text { indicated) }\end{array}$ & 0 & & \\
\hline T ier 2 (antibiotics may be indicated) & & 3 & 100 \\
\hline Sinusitis & 3 & 6 & 100 \\
\hline Pharyngitis & 6 & 8 & 100 \\
\hline Acute O titis media & 8 & 7 & 100 \\
\hline T onsillitis & 7 & & 75 \\
\hline T ier 3 (antibiotics not indicated as per recommendation) & & 3 & \\
\hline Allergic rhinitis & 4 & 22 & 100 \\
\hline Bronchitis / bronchiolitis & 22 & 69 & 73 \\
\hline Common cold/Influenza & 94 & & \\
\hline
\end{tabular}

\section{RESULTS}

T otal prescriptions of respiratory diseases studied were 173 , out of which 144 met the study criteria of acute respiratory infections. The prescriptions pertaining to the diagnoses of T uberculosis, Asthma, and Chronic obstructive pulmonary diseases were excluded. The majority, $74(60 \%)$, of the cases of RT I were children in the age group of $0-12$ years. T he average age was 16.5 SD 17.6. T here were 73 male and 67 female patients. Analysis of core prescribing indicators, including antibiotic prescribing, is shown in Table 1 . The prescriptions with antibiotics were $\mathrm{N}=118 \quad(82 \%)$ against the WHO standard of 20 to $26.8 \%$. Various categories of RT I showed an overuse of antibiotics by $78 \%$ in tier 3 diagnoses such as cold, influenza, allergic rhinitis, bronchitis, and bronchiolitis where no antibiotic is indicated ( $T$ able 2). Inappropriate antibiotics were prescribed in $75 \%$ of patients diagnosed with allergic rhinitis $(n-3 / 4), 73 \%$ with viral URT I (n-69/94), and 100\% with bronchitis (n-22). T he most prescribed antibiotics were Penicillin (53\%), followed by Cephalosporins (27\%), Fluoroquinolones (10.5\%), and $\mathrm{M}$ acrolides (7.5\%) ( $\mathrm{T}$ able 3). Analysis of other core prescribing indicators showed that the average number of medicines per prescription was 3.11 (SD 1.2, range 8) (T able 1). O ut of 433 medications prescribed, only $2.5 \% \quad(\mathrm{~N}=10)$ were prescribed according to their generic names, and 79\% (n-342) of the medicines were from the national drug list. Prescriptions with injections were only $1 \% \quad(\mathrm{~N}=3)$, much lower than the W H O standard of 13.4 to $24.1 \%$.

\section{DISCUSSION}

Drug utilization studies are an essential tool in improving the health care system nowadays. $T$ his is the first study on prescribing trends in upper respiratory infections in the region of Azad $\mathrm{K}$ ashmir. T he findings of this study show an overuse and inappropriate use of antibiotics along with a very low predominance of generic prescribing. There is a shortage of national studies on antibiotic prescribing patterns in RTI. Findings of this study of overuse $(82 \%)$ and inappropriate antibiotic prescription (78\%) are alarmingly high compared to percentages of antibiotics prescribed for tier 3 diagnosis in international studies $25 \%$ to $46.2 \%$ but comparable to the figure of a national study $76 \%{ }^{14,15}$. U nnecessary antibiotic prescriptions to all the children with bronchitis could be attributed to parent pressure or diagnostic uncertainty, which could prompt practitioners to write antibiotics to diagnose bronchitis as bacterial pneumonia. ${ }^{16}$ Another critical finding in this study is that $79 \%$ of antibiotics prescribed are broad-spectrum including macrolides and fluoroquinolones while aminopenicillins, which may sometimes be indicated in case of bronchitis or sinusitis, are only $19 \%$. Such overuse of broad-spectrum antibiotics causes avoidable adverse events, contributes to antimicrobial resistance Clostridium difficile infections, and unnecessary treatment costs. ${ }^{17} \mathrm{~T}$ here were no local institutional guidelines or national guidelines available for treating various respiratory tract infections. Interventional strategies to improve antibiotic use could be instituting antibiotic 
Table 3. Classes of antibiotics prescribed

\begin{tabular}{|c|c|c|c|}
\hline G roup of Antibiotics & $\mathrm{N}$ ame of Antibiotics & $\mathrm{N}$ umber prescribed $\mathrm{n}=119$ & Percentage of antibiotic prescribed $\%$ \\
\hline \multirow{2}{*}{ Penicillin } & Co-amoxiclav & 23 & 19 \\
\hline & Amoxil & 41 & 34 \\
\hline \multirow{2}{*}{ Cephalosporins } & Cephradine & 1 & 1 \\
\hline & Cefixime & 32 & 26 \\
\hline \multirow[t]{3}{*}{ M acrolides } & Erythromycin & 1 & 1 \\
\hline & Clarithromycin & 5 & 4.5 \\
\hline & Azithromycin & 2 & 2 \\
\hline \multirow[t]{3}{*}{ Fluoroquinolones } & Levofloxacin & 9 & 7.5 \\
\hline & Moxifloxacin & 2 & 2 \\
\hline & Ciprofloxacin & 1 & 1 \\
\hline T etracyclines & Doxycycline & 2 & 2 \\
\hline
\end{tabular}

prescription guidelines, antibiotic stewardship programs, and financial incentives for reduced prescribing or extra counseling and close monitoring through prescription audits. ${ }^{18}$ All 144 prescriptions contained antibiotic therapy without any microbiological evidence such as culture and sensitivities supporting the use of antimicrobials, which is alarming. This empirical use may be attributed to the lack of capacity, resources, and sufficiently trained staff to isolate bacteria and determine antibiotic susceptibility in BHUs, RHCs, and THQH, but this explanation is not justified for the DHQH, which is well equipped with all the required resources. $\mathrm{N}$ onetheless, irrational prescribing of antibiotics is among the leading causes of antimicrobial resistance in developing countries. According to the $\mathrm{W}$ orld $\mathrm{H}$ ealth Organization, antimicrobial resistance is one of the greatest challenges in public health that may lead to a post-microbial era in which common infections may increase mortality again. ${ }^{19,20}$ Analysis of other core prescribing indicators showed polypharmacy as an average number of drugs per prescription was 3.11, higher than the acceptable W H O reference range of 1.6 -1.8. $T$ hough the percentage of drugs prescribed from NEML was $80 \%$ and below the WHO standard of $100 \%$, this figure is better than the national average of $50 \%$ and figures $(72 \%)$ of low and middle-income countries. However, the meager percentage of drugs $(2 \%)$ as prescribed by their generic names as compared to national $(25 \%)$ and international averages (37 to $94 \%$ ) from low- and middle-income countries. ${ }^{21,22}$ There could be various factors for lack of generic prescribing, such as lack of local bioequivalence studies leading to an impression that generic medicines may be less effective, lobbying by interest groups for originator brands, and direct access of prescribers to pharmaceutical agents. ${ }^{23}$

\section{CONCLUSION}

The majority of patients' prescriptions attending outpatient clinics for common respiratory tract infections of viral origin in public health facilities in Mirpur Azad Kashmir contained overuse and inappropriate antibiotic prescribing along with polypharmacy and very limited use of generic prescribing.

\section{REFERENCE}

1. Havers FP, Hicks LA, Chung JR, Gaglani M, M urthy $K$, Zimmerman RK, Jackson LA, Petrie JG, M CL ean H Q, N owalk $M P$, Jackson $M L$. O utpatient antibiotic prescribing for acute respiratory infections during influenza seasons. JAM A network open. 2018 J un 1;1(2):e180243-.

2. HeP, Sun $Q$, Shi L, M eng Q. Rational use of antibiotics in the context of C hina's health system reform. BM J. 2019; 365.

3. L axminarayan $R, D$ use $A, W$ attal $C, Z$ aidi $A K, W$ ertheim $H F$, Sumpradit $N$. et al. Antibiotic resistance-the need for global solutions. L ancet Infect D is. 2013; 13(12):1057-98.

4. Ayukekbong JA, N temgwa M, Atabe AN. The threat of antimicrobial resistance in developing countries: causes and control strategies. Biomed Central. 2017; 6(1):1-8.

5. Zaidi S, N ishtar N A. Rational prescription \& use: a snapshot of the evidence from Pakistan and emerging concerns. Therapy. 2012; 19:20.

6. Atif M, Azeem M, Sarwar M R, M alik I, Ahmad W , H assan F et al. Evaluation of prescription errors and prescribing indicators in the private practices in Bahawalpur. J Chin M ed Assoc. 2018; 81(5):444-9.

7. W orld $\mathrm{H}$ ealth O rganization. $\mathrm{H}$ ow to investigate antimicrobial use in hospitals: selected indicators. $2^{\text {nd }}$ ed; 2012.p.79

8. Ghei P. How to investigate drug use in health facilities. Selected drug use indicators: W HO publications, Geneva, 87 pp., 1993. H ealth Policy. 1995;34(1):73-1.

9. M d Rezal RS, H assali M A, Alrasheedy AA, Saleem F, M d Y usof FA, Godman B. Physicians' knowledge, perceptions and behaviour towards antibiotic prescribing: a systematic review of the literature. Expert review of anti-infective therapy. 2015; 13(5):665-80.

10. Fleming-D utra KE, H ersh AL, Shapiro DJ, Bartoces M, Enns $E A$, File TM et al. Prevalence of inappropriate antibiotic prescriptions among US ambulatory care visits, 2010-2011. JAM A. 2016; 315(17):1864-73.

11. Ofori-Asenso, R, Brhlikova P, Pollock AM. Prescribing indicators at primary health care centers within the W HO 
African region: a systematic analysis (1995-2015). BM C Public $\mathrm{H}$ ealth 2016; $16: 724$

12. De Bruyne F, Ponçon A, G iai J et al. IN N or brand name drug prescriptions: a multilevel, cross-sectional study in general practice. Eur J Clin Pharmacol 2019; 75:275-283.

13. Atif M, M alik I, D awoud D, Gilani A, Ahmed N, Babar ZU . Essential Medicine List, Policies, and the $W$ orld $H$ ealth Organization. Encyclopedia of Pharmacy Practice and Clinical Pharmacy; Babar, ZU D, Ed.; E Isevier: O xford, U K. 2019:23949.

14. Rezal RS, H assali MA, Alrasheedy AA, Saleem F, Aryani M d Yusof $F, K$ amal $M$ et al. Prescribing patterns for upper respiratory tract infections: a prescription-review of primary care practice in Kedah, $\mathrm{M}$ alaysia, and the implications. Expert review of anti-infective therapy. 2015; 13(12):1547-56.

15. Silverman M, Povitz M, Sontrop JM , Li L, Richard L, C ejic S et al. antibiotic prescribing for nonbacterial acute upper respiratory infections in elderly persons. Ann. Intern. Med. 2017; 166(11):765-74.

16. Snyder $R L$, King $L M, H$ ersh $A L$, Fleming-Dutra $K E$. $U$ nnecessary antibiotic prescribing in pediatric ambulatory care visits for bronchitis and bronchiolitis in the U nited States, 2006-2015. Infection Control \& H ospital E pidemiology. 2020 16:1-4.

17. Ross-D egnan D, Laing R, Q uick J, Ali HM, O fori-Adjei D, Salako $L$ et al. A strategy for promoting improved pharmaceutical use: the International $\mathrm{N}$ etwork for Rational U se of D rugs. SO C. Sci. 1992; 35(11):1329-41.
18. Sanchez GV, Fleming-Dutra KE, Roberts RM, Hicks LA. Core elements of outpatient antibiotic stewardship. M orbidity and M ortality W eekly Report: Recommendations and Reports. 2016; 65(6):1-2.

19. Sharland $M, G$ andra $S, H$ uttner $B, M$ oja L, Pulcini $C$, Zeng $M$ et al. Encouraging $A W$ aRe-ness and discouraging inappropriate antibiotic use - the new 2019 Essential M edicines L ist becomes a global antibiotic stewardship tool. Lancet Infect Dis. 2019; 19(12):1278-80.

20. Zellweger RM, Carrique-M as J, Limmathurotsakul D, D ay NP, Thwaites GE, Baker S, Southeast Asia Antimicrobial Resistance $\mathrm{N}$ etwork. A current perspective on antimicrobial resistance in Southeast Asia. J. Antimicrob. Chemother. 2017; 72(11):2963-72.

21. H ussain S, M alik F, H ameed A, Parveen $G, R$ aja FY, Riaz $H$, et al. Pharmacoepidemiological studies of prescribing practices of health care providers of Pakistan: A cross-sectional survey. Afr. J. Pharmacy Pharmacol. 2011; 5(12):1484-93.

22. Hogerzeil HV, Ross-D egnan D, L aing RO, O fori-Adjei D, Santoso B, Chowdhury AA et al. Field tests for rational drug use in twelve developing countries. The Lancet. 1993; 342(8884):1408-10.

23. W outers $\mathrm{O}$ J, K anavos PG, M cK ee $\mathrm{M}$. Comparing generic drug markets in Europe and the U nited States: prices, volumes, and spending. M ilbank Q . 2017; 95(3):554-601. 